\title{
Embryonic Pax7-Expressing Progenitors Contribute Multiple Cell Types to the Postnatal Olfactory Epithelium
}

\author{
Barbara Murdoch, Casey DelConte, and Martín I. García-Castro \\ Department of Molecular, Cellular, and Developmental Biology, Yale University, New Haven, Connecticut 06520-8103
}

Prolonged neurogenesis driven by stem/progenitor cells is a hallmark of the olfactory epithelium (OE), beginning at the placodal stages in the embryo and continuing throughout adult life. Despite the progress made to identify and study the regulation of adult OE progenitors, our knowledge of embryonic $\mathrm{OE}$ precursors and their cellular contributions to the adult $\mathrm{OE}$ has been stalled by the lack of markers able to distinguish individual candidate progenitors. Here we identify embryonic OE Pax7+ progenitors, detected at embryonic day 10.5 (E10.5) in the olfactory pit with an antigen profile and location previously assigned to presumptive OE stem cells. Using Cre-loxP technology (Pax7-cre/ROSA YFP mice), we expose a wide range of derivatives, including CNS and olfactory neurons, non-neuronal cells, and olfactory ensheathing glia, all made from embryonic Pax7+ cells. Importantly, the expression of Pax7 in the embryonic OE is downregulated from E15.5, such that after birth, no Pax7+ cells are found in the 0E, and thus the progenitor population here identified is restricted to embryonic stages. Our results provide the first evidence for a population of Pax7-expressing embryonic progenitors that contribute to multiple $\mathrm{OE}$ lineages and demonstrate novel insights into the unique spatiotemporal patterning of the postnatal $\mathrm{OE}$.

\section{Introduction}

The olfactory epithelium (OE) is one of a few exclusive regions in the adult nervous system where lifelong neurogenesis occurs (Graziadei and Graziadei, 1979; Schwob, 2002). Neurogenesis and maintenance of the sense of smell is dependent on the biological responses of stem and/or progenitor cells. A common problem in stem cell biology however, is the limited availability of markers capable of identifying precursor cells whose ontogeny, in vivo niche, and lineage potential can be examined (Weissman et al., 2001).

The postnatal $\mathrm{OE}$ has a laminar structure with globose basal cell (GBC) and horizontal basal cell (HBC) progenitors in the basal region, olfactory receptor neurons (ORNs) in the midsection, and sustentacular cells at the apex. In the underlying lamina propria, olfactory ensheathing glia wrap around ORN axon bundles as they target the olfactory bulb in the CNS (Getchell et al., 1984; Farbman, 1992). Bowman's glands in the lamina propria produce mucous delivered through ducts that extend through the OE to the outer surface (Getchell et al., 1984; Farbman, 1992). In contrast, the embryonic OE lacks laminar structure and comprises mostly proliferating progenitors. Several cell types, such as HBCs and sustentacular cells, do not emerge until late embryonic or early postnatal development, with ORN numbers gradually

Received Feb. 17, 2010; revised May 27, 2010; accepted June 3, 2010.

This work was supported by a Seessel Postdoctoral scholarship (B.M.) and National Institutes of Health Grant R01 DE017914 (M.I.G.-C.). We thank the following colleagues for sharing the reagents that made this project possible: Charles Greer (antibodies), James Schwob (SUS4 antibody), Mario Capecchi (Pax7-cre mice), and Diane Krause (ROSA-YFP and ROSA LaCZ mice). We thank Dorothy Wierzbicki for Figure 4 artwork and Carson Miller and Elke Stein for technical advice and support.

Correspondence should be addressed to either Dr. Barbara Murdoch or Dr. Martín I. García-Castro, Department of Molecular, Cellular, and Developmental Biology, Yale University, P.0. Box 208103, New Haven, CT 06520-8103. E-mail: barbara.murdoch@yale.edu or martin.garcia-castro@yale.edu.

DOI:10.1523/JNEUROSCI.0867-10.2010

Copyright $\odot 2010$ the authors $\quad 0270-6474 / 10 / 309523-10 \$ 15.00 / 0$ increasing as embryonic development proceeds. However, the spatiotemporal contributions of embryonic olfactory progenitors to the postnatal $\mathrm{OE}$ are primarily unknown.

Although limited, studies using transgenic mice to genetically fate map embryonic progenitor descendants have helped to formulate our current understanding of embryonic OE lineage contributions, which have uncovered either neuron-restricted or glia-restricted embryonic progenitors. Labeled ORNs are detected throughout the OE of FoxG1-cre/reporter mice (Duggan et al., 2008), but regionally restricted to the dorsomedial OE in Nestin-cre/reporter mice (Murdoch and Roskams, 2008), whereas BLBP-cre/reporter mice label only olfactory ensheathing glia (Murdoch and Roskams, 2007). Markers of embryonic precursors with the capacity to produce postnatal neurons together with glia, or additional non-neuronal cells such as sustentacular cells, have not been identified.

In numerous tissues during embryonic development, mammalian Pax genes, transcription factors of the paired domain family, contribute to the regulation of cell proliferation, lineage specification, differentiation, migration, and survival (Lang et al., 2007; Blake et al., 2008). Pax genes also play a role in the development of the OE (Davis and Reed, 1996; LaMantia et al., 2000). For example, although Pax7 mutants have no obvious olfactory abnormality (Mansouri et al., 1996), Pax7 is expressed at early embryonic stages (Jostes et al., 1991; Stoykova and Gruss, 1994) in regions associated with Sox $2+$ putative OE stem cells (LaMantia et al., 2000; Beites et al., 2005; Kawauchi et al., 2005; Chen et al., 2009), whose lineage contributions are unknown.

Here we investigate the expression of Pax7 before and during $\mathrm{OE}$ ontogeny and use Cre-loxP technology to lineage trace Pax7 progeny to investigate the contributions made by Pax7expressing embryonic progenitors. Our results reveal novel spatiotemporal patterning of the postnatal OE and identify, for the 
first time, embryonic precursors expressing Pax7 that generate multiple nervous system and chemosensory lineages, including CNS, vomeronasal and olfactory neurons, olfactory glia, and non-neuronal cells.

\section{Materials and Methods}

Tissue preparation. Adult and postnatal mice were killed in a $\mathrm{CO}_{2}$ chamber, perfused with cold $\mathrm{PBS}$ and $4 \%$ paraformaldehyde (PFA) in PBS, and postfixed in $4 \%$ PFA at $4^{\circ} \mathrm{C}$ (Murdoch and Roskams, 2008). Embryos were immersion fixed in $4 \%$ PFA overnight. The day of vaginal plug was defined as embryonic day 0.5 (E0.5). Tissues were cryoprotected in sucrose, embedded in Tissue-Tek medium (OCT; Sakura Finetek), and frozen in liquid nitrogen. Twelve-micrometer sections were stored at $-20^{\circ} \mathrm{C}$ for subsequent analysis.

Immunohistochemistry. Sections were immersed in PBS, permeabilized in $0.1 \%$ Triton X-100/PBS, and blocked with 4\% normal serum before primary antibody incubation. Secondary antibodies (1:200) used were of specific isotypes conjugated to biotin (Vector Laboratories) or Alexa 568 or Alexa 488 (Invitrogen). Before blocking, Sus 4 and transcription factor detection was enhanced by a $15-60 \mathrm{~s}$ incubation of the sections with $0.12 \%$ trypsin/EDTA (Invitrogen) (longer duration for older ages), followed by washing in PBS. Primary antibodies used were as follows: mouse anti-rat $\beta$ III tubulin (neuron-specific tubulin-TUJ1; 1:500; Covance); mouse anti-mammalian achaete-scute homolog 1 (Mash1; 1:100; BD Pharmingen); mouse anti-Pax7 and -Pax6 (Developmental Studies Hybridoma Bank; developed by A. Kawakami and C. P. Ordahl); rabbit anti-green fluorescent protein [GFP; 1:400; to detect yellow fluorescent protein (YFP); Millipore]; and Sox2 (1:300; R \& D Systems). Note that all YFP panels show anti-GFP immunofluorescence that was confirmed using nonfluorescent immunoperoxidase (VIP) immunohistochemistry with antiGFP antibodies (supplemental Fig S2, available at www.jneurosci.org as supplemental material), with the exception of the YFP-containing panels in Figure $2 B$ and supplemental Fig S2C (available at www.jneurosci.org as supplemental material), which show endogenous YFP fluorescence. Gift antibodies were mouse anti-rat Sus4 (1:100) from Dr. J. Schwob (Tufts University, Boston, MA) and goat polyclonal olfactory marker protein (OMP; 1:5000) from C. Greer (Yale University, New Haven, CT). Nuclei were stained with $0.5 \mu \mathrm{g} / \mathrm{ml}$ diaminopyridine imidazole (DAPI), and sections were coverslipped in Vectashield (Vector Laboratories) for fluorescent antigens or $50 \%$ glycerol for VIP. Images were visualized with either a Nikon dissecting scope or a Nikon Eclipse 80i microscope using a SPOT camera (SPOT Diagnostic Instruments) with SPOT software (version 4.5). Confocal images were collected on a Zeiss LSM 510 microscope with ZEN software (version 5) and processed using Image (version 1.43r). All images were compiled using Adobe Photoshop 7.0.

Quantitative real-time PCR. Total RNA was isolated from E11.5 mouse embryos using RNAzol B reagent (Tel-Test). Total RNA was reverse transcribed with the iScript cDNA Synthesis kit (Bio-Rad) according to the manufacturer's instructions. Real-time PCR was performed in triplicate using the iQ SYBR Green Super Mix in a Bio-Rad iQ5. Each reaction contained cDNA template, $1 \times$ iQ SYBR Green Super Mix, and 300 $\mu \mathrm{M}$ primers. Each plate was run in triplicate. Conditions for amplification were as follows: $3 \mathrm{~min}$ at $95^{\circ} \mathrm{C}$, followed by 40 cycles of $10 \mathrm{~s}$ at $95^{\circ} \mathrm{C}$, $30 \mathrm{~s}$ at $55^{\circ} \mathrm{C}$, and $30 \mathrm{~s}$ at $72^{\circ} \mathrm{C}$. Melting-curve analysis was performed from $55^{\circ} \mathrm{C}$ to $95^{\circ} \mathrm{C}$, with $1^{\circ} \mathrm{C} / \mathrm{s}$ transitions. The primers used were as follows: Pax7F, 5'-GCTACCAGTACAGCCAGTATG-3'; Pax7R, 5'-GTCACTAAGCATGGGTAGATG-3' (McKinnell et al., 2008); $\beta$-actinF, $5^{\prime}$-AAGTGTGACGTTGACATCCG- ${ }^{\prime}$; and $\beta$-actinR, $5^{\prime}$-GATCCAC-
ATCTGCTGGAAGG-3'. Cycle threshold values and amplification curves were obtained using iQ5 Optical System software (version 2.0; Bio-Rad). All data were normalized to $\beta$-actin. Relative Pax7 expression was calibrated against wild-type controls where $\Delta \mathrm{Ct}_{1}=$ wild-type $\mathrm{Ct}-$ Pax7 cre or Pax7 null Ct; $\Delta \mathrm{Ct}_{2}=$ wild-type $\mathrm{Ct}-\beta$-actin Ct; relative Pax7 expression was calculated as $2^{(\Delta \mathrm{Ct1}-\Delta \mathrm{Ct} 2)}$.

Transgenic mice. All experimental procedures were performed in accordance with the Yale Animal Resources Center and Institutional Animal Care and Use Committee policies. Pax7-cre mice (C57BL/6) obtained from M. Capecchi (University of Utah, Salt Lake City, UT) (Keller et al., 2004) were

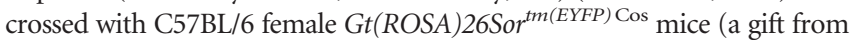
D. Krause, Yale University, New Haven, CT) expressing enhanced YFP from the ROSA26 locus (termed ROSA YFP) (Srinivas et al., 2001). Gtrosa26 $6^{\text {tm ISor }}$ (expressing $\beta$-galactosidase protein from the ROSA26 locus) (Soriano, 1999) produced a similar reporter expression pattern after Pax7-cremediated excision. Pax7-cre/ROSA YFP double-transgenic mice, where Cre recombinase expression is under the control of the endogenous Pax7 regulatory elements, express YFP without disrupting Pax7 function (Keller et al., 2004). Pax7 LacZ mutant mice were obtained from A. Mansouri (University of Göttingen, Göttingen, Germany) and have been reported previously (Mansouri et al., 1996). Mice were genotyped by PCR for Pax7, Cre (Keller et al., 2004), and YFP. Pax7 primers located within Pax7 exon $10\left(5^{\prime}\right.$ GCTCTGGATACACCTGAGTCT-3', 5'-TCGGCCTTCTTCTAGGTTCTGCTC-3'; ck118 and ck256, respectively; 465 bp product) were combined with an IRES-Cre primer (5'-GGATAGTGAAACAGGGGCAA-3'; ck172; 340 bp product); ROSA YFP primers were Rosal (5'-AAAGTCGCTCTGAGTTGTTAT-3') and Rosa3 (5'-GGAGCGGGAGAAATGGATATG-3'; wildtype ROSA locus, 650 bp product); and Rosa 3 and YRF (5'-CGACCACTACCAGCAGAACA-3'; ROSA26 YFP, 850 bp product). PCR parameters were as follows: 35 cycles of $95^{\circ} \mathrm{C}$ at $30 \mathrm{~s}, 58^{\circ} \mathrm{C}$ at $30 \mathrm{~s}, 72^{\circ} \mathrm{C}$ at $60 \mathrm{~s}$. Efficiency of Cre-lox recombination was verified by the specific colocalization of Pax7 with YFP proteins in Pax7-cre/ROSA YFP embryos and the similar reporter expression patterns detected in Pax7-LacZ (Relaix et al., 2004), Pax7-Zs-green (Bosnakovski et al., 2008), and Pax7-cre/Gtrosa26 ${ }^{\text {tmlsor }}$ (Keller et al., 2004) mice.

For each time point, at least three Pax7-cre/reporter positive embryos, pups, or mice were analyzed. Sections from the rostral, middle, and caudal OE for coronal sections, or lateral to medial for sagittal sections, were sam- 

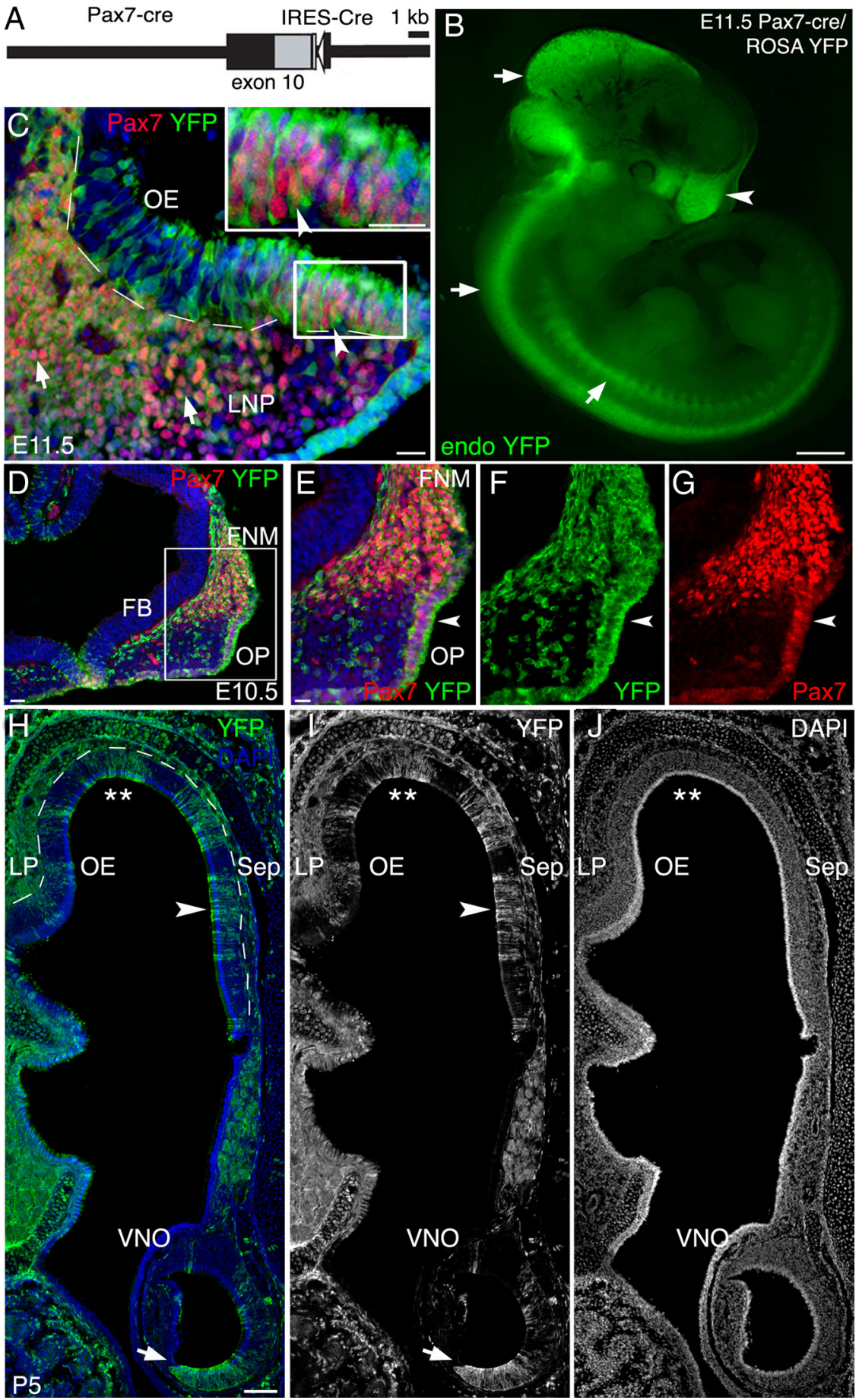

Figure 2. Fate-mapping Pax7+ progenitors in the OE of Pax7-cre/ROSA YFP transgenic mice. $\boldsymbol{A}$, The Pax7-cre construct has an encephalomyocarditis internal ribosomal entry site with the Cre coding sequence (IRES-Cre; gray box) inserted into the $3^{\prime}$ untranslated region following the exon 10 (black box) stop codon of the Pax7 locus (represented by the black line) (Keller et al., 2004). Pax7-driven Cre expression occurs without disrupting normal Pax7 function. The arrowhead indicates a remaining flippase recognition target site. $\boldsymbol{B}$, In E11.5 Pax7-cre/ROSA YFP whole-mount embryos, endogenous YFP expression (green) is detected in the midbrain, the hindbrain, the entire anteroposterior axis of the neural tube, the dorsal root ganglia (arrows), and the frontonasal region (arrowhead). C, Pax7 (red) and YFP can be detected in mesenchymal cells of the lateral nasal process (LNP; arrows) and the developing $0 \mathrm{E}$ (arrowhead; boxed region magnified in inset) of transverse E11.5 sections. D-G, Pax7, together with YFP expression, is detected in the frontonasal mesenchyme (FNM) and olfactory placode/pit (OP) at E10.5 (arrowhead), the first developmental stage in which we recognized olfactory tissue. The boxed region in $\boldsymbol{D}$ is magnified in $\boldsymbol{E}-\mathbf{G}$. $\boldsymbol{H}-\boldsymbol{J}$, Immunofluorescence on P5 Pax7-cre/ROSA YFP mice show YFP + cells in the OE (arrowhead) and vomeronasal organ (VNO; arrow) of coronal sections. DAP nuclear stain is blue in $\boldsymbol{C}-\boldsymbol{E}$ and $\boldsymbol{H}$. Individual signals are from $\operatorname{Pax} 7(\boldsymbol{G}), \operatorname{YFP}(\boldsymbol{B}, \boldsymbol{F}, \boldsymbol{I})$, and DAPI (J); Double asterisks indicate dorsal recess. Sep, Septum; $L P$, lamina propria; $F B$, forebrain. The dashed line indicates the basal lamina. Scale bars: $\boldsymbol{B}, 1 \mathrm{~mm} ; \boldsymbol{C}, \boldsymbol{E}-\boldsymbol{G}$ (in (C, E), $100 \mu \mathrm{m} ; \boldsymbol{D}, 200 \mu \mathrm{m} ; \boldsymbol{H}-J$ (in $\boldsymbol{H}), 500 \mu \mathrm{m}$. pled and tested for YFP+ cells from each mouse. To determine the rostrocaudal YFP expression pattern, every 10th section was sampled from adult ( $\geq 60 \mathrm{~d}$ ) Pax7-cre/ROSA YFP mice.

Cell quantitation. For YFP+ cell quantitation, at least three sections per animal, from the rostral, middle, and caudal OE or $72 \mu \mathrm{m}$ flanking the Pax7-expressing region in the E11.5 $\mathrm{OE}$, were assayed to adequately sample the $\mathrm{OE}$, from each of three animals per developmental stage. Total YFP+ cells per section were divided by the length of $\mathrm{OE}$ measured, using ImageJ (version 1.43r). Average total cells per millimeter, assessed by DAPI nuclear stain, were calculated after measuring $100 \mu \mathrm{m}$ regions of $\mathrm{OE}$ from each turbinate visible on the sections, or all of the visible OE for E11.5.

\section{Results}

Pax7 expression in the mouse OE during ontogeny

Pax7 protein expression can be detected in mouse embryos at E7.5-E8.5 in the lateral region of the cephalic neural folds, in the caudal neural plate neuroepithelium, and in the cephalic mesenchyme (supplemental Fig S1, available at www.jneurosci.org as supplemental material), in agreement with previous in situ expression beginning at E8 (Jostes et al., 1991). Pax7 is more widely expressed in the E9.5 developing hindbrain, forebrain, and frontonasal mesenchyme (supplemental Fig S1, available at www.jneurosci.org as supplemental material) and is reported in the nose at stages E10-E14.5 (Jostes et al., 1991; Lang et al., 2003). A detailed study showed that E10.5 embryos express Pax7 in the lateral frontonasal mesenchyme and lateral margin of the nasal pit (LaMantia et al., 2000), which was confirmed here (see Fig. 2). To better understand the role of Pax7 progenitors during olfactory development, we used immunohistochemistry to determine the changes in Pax7 expression from embryonic to adult development. By E11.5, the mesenchyme of the lateral nasal process robustly expressed Pax7, which in the $\mathrm{OE}$ showed a ventral to dorsomedial gradient (highest to lowest) (Fig. 1A). Pax7 was not readily detected in the E15.5 OE but was found in cells closely juxtaposed to the epithelial-mesenchymal border (Fig. 1B). Similarly, the P5 lamina propria, but not the OE, contained $\mathrm{Pax} 7+$ cells (Fig. 1C). Neither the adult OE nor the lamina propria contained cells with detectable Pax7 expression (three mice sampled) (Fig. 1D). Thus, the cellular location of Pax7+ cells and dynamic expression levels during development suggest that Pax7 precursors may contribute to multiple cell types in the mature OE. 
Table 1. Quantitation of YFP + cells in the olfactory epithelium of Pax7-cre/ROSA YFP mice during ontogeny

\begin{tabular}{lllccc}
\hline & $\begin{array}{l}\text { Average millimeter of 0E } \\
\text { analyzed per animal }\end{array}$ & $\begin{array}{l}\text { Average YFP+ } \\
\text { cells per animal }\end{array}$ & $\begin{array}{l}\text { Average YFP+ } \\
\text { cells per millimeter }\end{array}$ & $\begin{array}{l}\text { Average total } \\
\text { cells per millimeter }\end{array}$ & $\begin{array}{l}\text { Percentage of total } \\
\text { cells that are YFP }+\end{array}$ \\
\hline E11.5 $(n=3)$ & 3.3 & 335 & $102.8 \pm 9.1^{*}$ & $630 \pm 36.9$ & 16.3 \\
P5 $(n=3)$ & 8.0 & 710 & $87.9 \pm 21.2^{*}$ & $1307 \pm 16.6$ & 6.7 \\
Adult $(n=3)$ & 60.4 & 755 & $16.2 \pm 2.1$ & $1796 \pm 43.0$ & 0.9 \\
\hline
\end{tabular}

Cells were counted from three sections per animal, three animals per stage, as outlined in Materials and Methods. Values indicate means ( \pm SEM). The percentage of YFP + cells was derived from the average YFP + cells per millimeter divided by the average total cells per millimeter, multiplied by $100 .{ }^{*} p<0.0001$ versus adult.

Fate mapping Pax7+ embryonic progenitors in Pax7-cre/ROSA YFP transgenic mice

To test the lineage contributions of Pax7expressing cells in the $\mathrm{OE}$, we crossed Pax7-cre transgenic mice, where an IRESCre cassette was inserted into exon 10 of Pax7 (Fig. 2A) (Keller et al., 2004), with Gt(ROSA)26Sor ${ }^{\text {tm(EYFP) Cos }}$ reporter mice (hereafter termed ROSA YFP) (Srinivas et al., 2001). In Pax7-cre/ROSA YFP doubletransgenic mice, Cre recombinase expression is under the control of the endogenous Pax7 regulatory elements without disrupting Pax7 function. Pax7-dependent Cre expression mediates an excision event that removes a floxed stop cassette, thus allowing continued YFP expression from the ROSA locus in Pax7-expressing cells and their progeny even after Pax7 expression ceases. In whole-mount embryos, we detected endogenous YFP expression in the developing midbrain, hindbrain, neural tube, somites, dorsal root ganglia, and frontonasal region (Fig. 2B) similar to endogenous Pax7 expression. The YFP reporter expression pattern seen in Pax7-cre/ROSA YFP embryos is consistent with that reported previously using Pax7-LacZ (Relaix et al., 2004), Pax7ZsGreen (Bosnakovski et al., 2008), and Pax7-cre/ROSA LacZ mice (Keller et al., 2004), where LacZ and ZsGreen identify Pax7-expressing cells and their immediate or lifelong progeny.

Sections from the frontonasal region of E11.5 Pax7-cre/ROSA YFP mice revealed Pax7+ YFP-negative cells and Pax7+YFP+ cells, which likely represent cells that only recently initiated Pax7 expression and display a delay between excision and detectable levels of reporter, respectively. Similar delays in Cre-mediated reporter expression have been reported before (Joyner and Zervas, 2006; Murdoch and Roskams, 2008). Additionally, Pax7-negative YFP + cells, the progeny of Pax7expressing precursors, which had excised and ceased to express Pax7, were also detected (Fig. 2C). At E10.5, most to all Pax7-expressing cells in the frontonasal mesenchyme and developing OE coexpress YFP (Fig. $2 D-G$ ), illustrating the faithful expression of the transgene together with Pax7. Multiple controls ensured the fidelity of our YFP detection in Pax7/reporter transgenic mice [littermate controls without either Pax7-cre or ROSA-YFP alleles, nonfluorescent immunohistochemistry methods, and secondary antibody-only controls (supplemental Fig S2, available at www.jneurosci.org as supplemental material)]. Together, this evidence validates the use of Pax7-cre/ROSA YFP transgenic reporter mice to map Pax7 progeny in olfactory lineages.
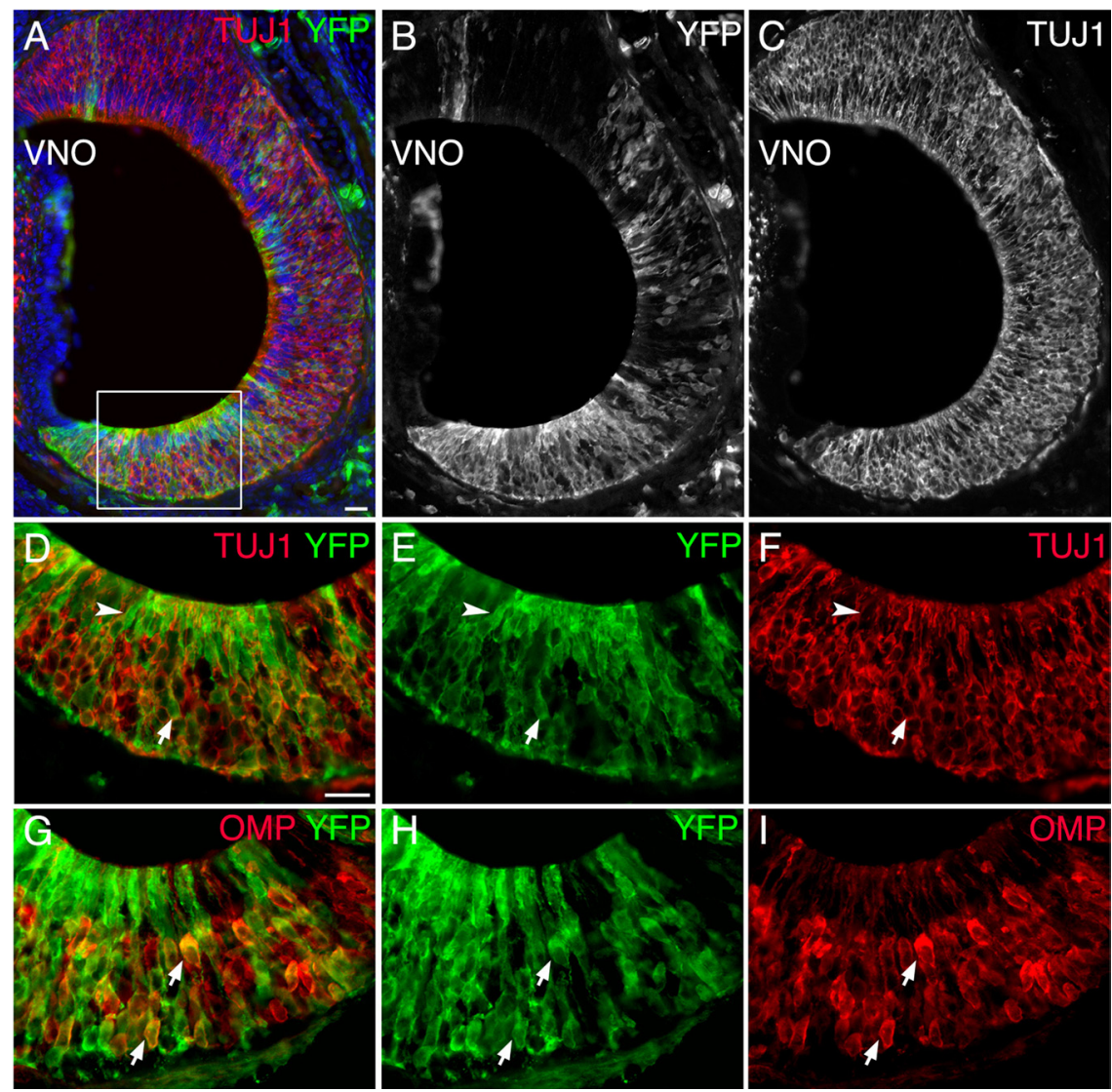

Figure 3. The Pax7 lineage contributes to vomeronasal sensory neurons. $\boldsymbol{A}-\boldsymbol{I}$, The P5 vomeronasal organ (VN0) contains arrowheads), or $0 M P+$ (red; $\boldsymbol{G}-\boldsymbol{I}$, arrows). The boxed region in $\boldsymbol{A}$ is magnified in $\boldsymbol{D}-\boldsymbol{F}$. Individual signals are from $\mathrm{YFP}(\boldsymbol{B}, \boldsymbol{E}, \boldsymbol{H})$, TUJ1 $(\boldsymbol{C}, \boldsymbol{F})$, or OMP $(\boldsymbol{I})$; DAPI nuclear stain is blue in $\boldsymbol{A}$. Scale bars: $\boldsymbol{A}-\boldsymbol{C}$ (in $\boldsymbol{A}), \boldsymbol{D}-\boldsymbol{I}$ (in $\boldsymbol{D}), 100 \mu \mathrm{m}$.

To determine the contribution of embryonic Pax7+ progenitors to the postnatal OE, we tested for YFP+ reporter cells in postnatal day 5 (P5) tissue. YFP + Pax7 progeny are detected in punctate regions of multiple laminae throughout the P5 OE and the vomeronasal organ, a specialized chemosensory organ (Fig. $2 H-J)$. In the OE, each P5 animal $(n=3$ for this and all subsequent quantitation) averaged $710 \mathrm{YFP}+$ cells, comprising $87.9 \pm 21.2 \mathrm{YFP}+$ cells $/ \mathrm{mm}$ of $1307 \pm 16.6$ total cells $/ \mathrm{mm}$ $(6.7 \% ; p<0.0001$ vs adult) (Table 1$)$. The head region also included YFP + cells in the septal cartilage, head mesenchyme, and nasal glands (Fig. $2 \mathrm{H}, \mathrm{I}$ ). These results show that embryonic Pax7 precursors contribute to multiple cell lineages that include chemosensory cells.

Subpopulations of chemosensory neurons and sustentacular cells arise via a Pax7 lineage

Using cell-type-specific antigens, we identified the cell types expressing YFP in the P5 vomeronasal organ. Subpopulations of TUJ1+ ( $\beta$ III neuron-specific tubulin) and OMP-positive vome- 

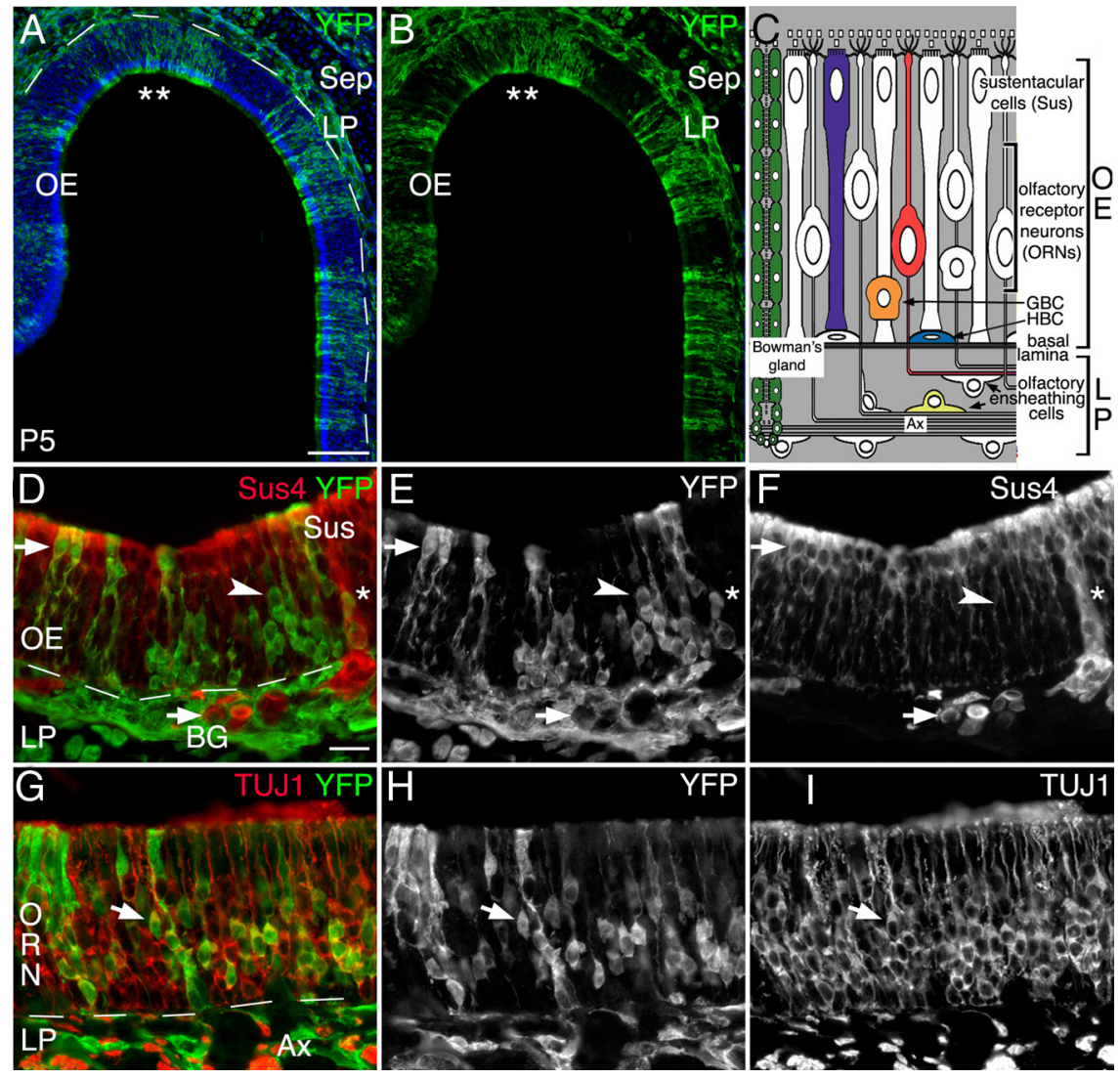

Figure 4. Subpopulations of sustentacular cells and ORNs arise via a Pax7 lineage. $\boldsymbol{A}, \boldsymbol{B}$, Coronal sections from P5 Pax7-cre/ROSA YFP mice show YFP + (green) cells in the $0 E$, throughout the lamina propria (LP) and in cartilage of the septum (Sep). DAPI is blue in $\boldsymbol{A}$. C, Diagram showing the laminar and cellular organization of the postnatal OE that includes from apex to basal lamina, sustentacular cells, ORNs, GBCs, and HBCs; olfactory ensheathing cells, Bowman's glands, and ORN axon bundles are beneath the basal lamina in the lamina propria. D-F, YFP + cells are detected in the apical OE in a subpopulation of Sus $4+$ (red) sustentacular cells (Sus; apical arrow) and below the apex in Sus4-negative cells (arrowhead). In the LP, Sus4+ cells of Bowman's gland (BG; arrow) do not appear to express YFP, even though YFP + cells are detected throughout. Cells of Bowman's ducts that emerge into the OE (asterisk), can express YFP. G-I, A subpopulation of ORNs (TUJ1+; red) express YFP (arrows). Double asterisks indicate dorsal recess. Scale bars: $\boldsymbol{A}, \boldsymbol{B}$ (in $\boldsymbol{A}$ ), $\boldsymbol{D}-\boldsymbol{I}$ (in $\boldsymbol{D}$ ), $100 \mu \mathrm{m}$. Ax, axon bundles.

ronasal receptor neurons expressed YFP in their cell bodies, dendrites, and axons (Fig. 3A-I). YFP + vomeronasal neurons were seen throughout the apical-basal axis, indicative of both V1R and V2R receptor neurons, respectively (Dulac, 2000).

Within the OE and the underlying lamina propria, multiple cells expressed YFP (Fig. 4A,B), whose location and morphology (summarized in Fig. 4C) were combined with candidate antigens in an effort to provide specific identity. The Sus 4 antigen identifies sustentacular cells and Bowman's duct cells in the OE and Bowman's glands in the lamina propria (Goldstein and Schwob, 1996). With their cell bodies in the apical OE and processes spanning the height of the OE, P5 sustentacular cells represent $251 \pm$ 2.9 Sus $4+$ cells $/ \mathrm{mm}$, of which $4.9 \pm 0.7$ cells $/ \mathrm{mm}(1.9 \%)$ are $\mathrm{YFP}+$ (Fig. 4D-F; Table 2). Sus4+ cells found in Bowman's glands did not appear to express YFP (29 glands, three animals), but $10.4 \pm 1.9 \%$ of the 46 ducts examined contained YFP + duct cells (Fig. 4D-F). Coexpression of YFP with celltype-specific antigens, including Sus4, was confirmed by confocal microscopy (Fig S3, available at www.jneurosci.org as supplemental material).

In the middle OE layers, the cell bodies of TUJ1+ immature ORNs express YFP, as do their axons, dendrites, and dendritic knobs (Fig. 4G-I). YFP + mature OMP+ ORNs were detected in P5 (data not shown) and adult animals (Fig S4, available at www.jneurosci.org as supplemental material). In P5 mice, of the $944 \pm 16.8$ total ORNs/mm, $80.6 \pm 6.2(8.5 \%)$ express YFP ( $p<2 \times 10^{-5}$ vs adult) (Table 2$)$. Approximately $3 \%$ of basal cells $(3.7 \pm 0.7$ YFP + cells $/ \mathrm{mm}$ from a total of $112 \pm 1.1$ basal cells/mm) express YFP ( $p<0.02$ vs adult) (Table 2).

The adult OE averaged $755 \mathrm{YFP}+$ cells (Table 1 ) with $16.2 \pm 2.1 \mathrm{YFP}+$ cells $/ \mathrm{mm}$ and $1796 \pm 43.0$ total cells/mm $(0.9 \%)$ (Table 1). YFP was expressed in $\sim 1 \%$ of total sustentacular cells and ORNs and in $0.004 \%$ of basal cells (Table 2 ). Within the YFP population of both adult and $\mathrm{P} 5$ animals, ORNs, sustentacular cells, and basal cells had the highest to lowest distribution of YFP + cells, respectively (Table 3 ).

A more than twofold increase of YFP+ cells was consistently detected unilaterally compared with contralaterally (but not on the same side in all animals; $n=$ 3 per time point), in the P5 (121.8 \pm 34.5 vs $54.2 \pm 16.2 ; p<0.05)$ and adult $(16.9 \pm 0.2$ vs $8.2 \pm 2.0 ; p<0.05) \mathrm{OE}$, indicating a bilateral asymmetry in Pax7-derived progeny.

To test whether the insertion of the Cre recombinase gene into the Pax7 locus could modify Pax7 expression and potentially account for the nonuniform pattern of YFP + cells in the OE, we compared the level of Pax7 expression in transgenic embryos homozygous for Pax7-cre with nontransgenic wild-type embryos (three embryos per genotype). Quantitative reverse transcription-PCR showed no significant difference in the relative expression of Pax7 in wild-type compared with Pax7-cre homozygous embryos but significant differences in both compared with Pax7 null controls $(p<0.001)$ (supplemental Fig S5, available at www.jneurosci.org as supplemental material). Likewise, neither the OE $(85.5 \pm 1.8 \%$ vs $87.3 \pm 1.5 \%)$ nor the frontonasal mesenchyme $(98.7 \pm 0.7 \%$ vs $98.1 \pm 1.0 \%)$ revealed any significant differences $(p>0.05)$ in the percentage of Pax7+ cells in Pax7-cre homozygotes compared with wild-type controls, respectively (supplemental Fig S5, available at www. jneurosci.org as supplemental material). These analyses show that Pax7 expression is stable after Cre insertion and suggest that Pax7 instability cannot account for the unique expression patterns detected in olfactory YFP + cells. Our results demonstrate that Pax7 embryonic progenitors contribute diverse cell types in unique patterns to the perinatal and adult $\mathrm{OE}$ and vomeronasal organ.

\section{Pax7 precursors produce olfactory ensheathing glia}

The postnatal lamina propria contains multiple cell types including olfactory ensheathing glia, mesenchymal cells, connective tissues, blood vessels, and fibroblasts. Of particular interest because of their possible use in therapies of spinal cord injury (for review, see Raisman and Li, 2007; Richter and Roskams, 2008; Kocsis et al., 2009) are the olfactory ensheathing glia. Olfactory ensheathing glia are a special type of glial cell that supports the growth of olfactory axons from the peripheral OE to their CNS target, the 
olfactory bulb, where they form the nerve fiber layer. Identified by their morphology and location, immediately adjacent to and surrounding TUJ1 + axon bundles in the lamina propria, YFP+ OECs were found in P5 and adult Pax7cre/ROSA YFP mice (Fig. $5 A-D$; supplemental Fig S3, available at www.jneurosci.org as supplemental material), where $94.5 \pm 0.5 \%$ of adult OECs are YFP + (1163 OECs counted). A strong YFP signal is also evident in the nerve fiber layer surrounding the olfactory bulb in the CNS (Fig. 5E,F). These results demonstrate that Pax7 derivatives contribute to various cell types in the lamina propria, which include olfactory ensheathing glia found both in the peripheral and central nervous systems.

The Pax7 lineage includes subsets of Pax6-, Sox2-, Mash1-, and intercellular adhesion molecule-1-expressing postnatal olfactory progenitors

To more precisely identify cells arising via a Pax7 lineage and further elucidate their cellular diversity, we assessed the expression of cell-type-specific transcription factors and cell surface molecules in P5 Pax7cre/ROSA YFP mice together with YFP. The Pax6 transcription factor is required for OE development and is expressed postnatally in basal cells, sustentacular cells, and Bowman's gland/duct cells (Davis and Reed, 1996). Sox2, an Sryrelated HMG (high mobility group) box transcription factor, is expressed in apical and basal cells in the embryonic (Kawauchi et al., 2004; Beites et al., 2005) and postnatal OE. In P5 Pax7cre/ROSA YFP animals, YFP together with either Sox 2 or Pax6 OE expression are detected in a subpopulation of sustentacular and basal cells (Fig. $6 A-H)$. In the lamina propria, YFP + cells closely juxtapose Sox2+ cells of Bowman's glands (Fig. 6F).

To test whether GBC or HBC progenitors could descend from Pax7 precursors, we monitored the expression of the basic helix-loop-helix transcription factor Mash1 (Gordon et al., 1995; Cau et al., 1997; Shou et al., 1999) and the intercellular adhesion molecule-1 (ICAM-1) (Carter et al., 2004), respectively. Mash1+ cells are detected in the basal layers in addition to the neuronal and sustentacular cell layers of the P5 Pax7cre/ROSA YFP OE (Fig. 6I-L), subsets of which coexpress YFP (Fig. 6J-L). Most ICAM-1+ HBCs do not coexpress YFP, but rare ICAM-1+YFP+ cells could be detected in regions devoid of YFP + ORNs and sustentacular cells (Fig. 6M-O). These results show that subsets of multiple postnatal olfactory progenitors descend from Pax7+ precursors.

\section{Subpopulations of embryonic olfactory progenitors arise via the Pax7 lineage}

Expression of YFP was used to test for the temporal contributions of YFP + cells before and during olfactory pit development. Rare YFP + cells were detected in the cephalic mesenchyme and lateral neural folds of E8.5 Pax7cre-ROSA YFP embryos, whereas more abundant contributions to the hindbrain, forebrain, and frontonasal region were first seen by E9.5 that persisted to E10.5 (supplemental Fig S6, available at www.jneurosci.org as supplemental material). Several cells in the E10.5 frontonasal mesenchyme were Pax7+YFP+, as were cells in the olfactory pit, the only
Table 2. Contribution of YFP+ cells to total cells as a function of cell subtype

\begin{tabular}{lccl}
\hline & $\begin{array}{l}\text { YFP }+ \\
\text { cells } / \mathrm{mm}\end{array}$ & $\begin{array}{l}\text { Total } \\
\text { cells } / \mathrm{mm}\end{array}$ & $\begin{array}{l}\text { Percentage of YFP + cells } \\
\text { (YFP+ per total cells/mm)* } 100\end{array}$ \\
\hline P5 cell type $(n=3)$ & & & \\
$\quad$ Sus & $4.9 \pm 0.7$ & $251 \pm 2.9$ & 1.9 \\
ORN & $80.6 \pm 6.2$ & $944 \pm 16.8$ & $8.5^{*}$ \\
BC & $3.7 \pm 0.7$ & $112 \pm 1.1$ & $3.3^{* *}$ \\
Adult cell type $(n=3)$ & & & \\
$\quad$ Sus & $2.3 \pm 0.3$ & $256 \pm 6.7$ & 0.9 \\
ORN & $13.7 \pm 1.6$ & $1317 \pm 39.3$ & 1.0 \\
BC & $0.009 \pm 0.002$ & $223 \pm 4.3$ & 0.004 \\
\hline
\end{tabular}

Cells were counted from rostral, middle, and caudal sections of $0 \mathrm{E}(3$ animals per stage). Values represent means \pm SEM. Sus, Sustentacular cell; $0 \mathrm{RN}$, olfactory receptor neuron; $\mathrm{BC}$, basal cell. . $p<2 \times 10^{-5}$; ${ }^{* *} p<0.02$. P5 versus adult.

Table 3. Contribution of YFP + cells to each cell subtype as a function of total YFP+ cells in the olfactory epithelium of Pax7-cre/ROSA YFP mice

\begin{tabular}{lccc}
\hline & \multicolumn{3}{l}{ Cell subtype distribution of YFP+ cells } \\
\cline { 2 - 4 } & Basal cells & Olfactory neurons & Sustentacular \\
\hline E11.5 $(n=3)$ & nd & $43 \%$ & nd \\
P5 $(n=3)$ & $4.2 \pm 0.8 \%$ & $91.7 \pm 1.3 \%$ & $5.5 \pm 0.5 \%$ \\
Adult $(n=3)$ & $0.68 \pm 0.2 \%$ & $84.1 \pm 0.6 \%$ & $15.2 \pm 0.9 \%$ \\
\hline
\end{tabular}

Cell counts were derived from three sections per animal, three animals per developmental stage. Values indicate means ( \pm SEM). The percentage of YFP + cells for each subtype was calculated by dividing the average number of YFP+ cells for each subtype by the total number of YFP + cells, multiplied by 100. nd, Not done because the antigens used to identify these cell types are not expressed at this developmental stage. ${ }^{*} p<0.0001$ versus adult.
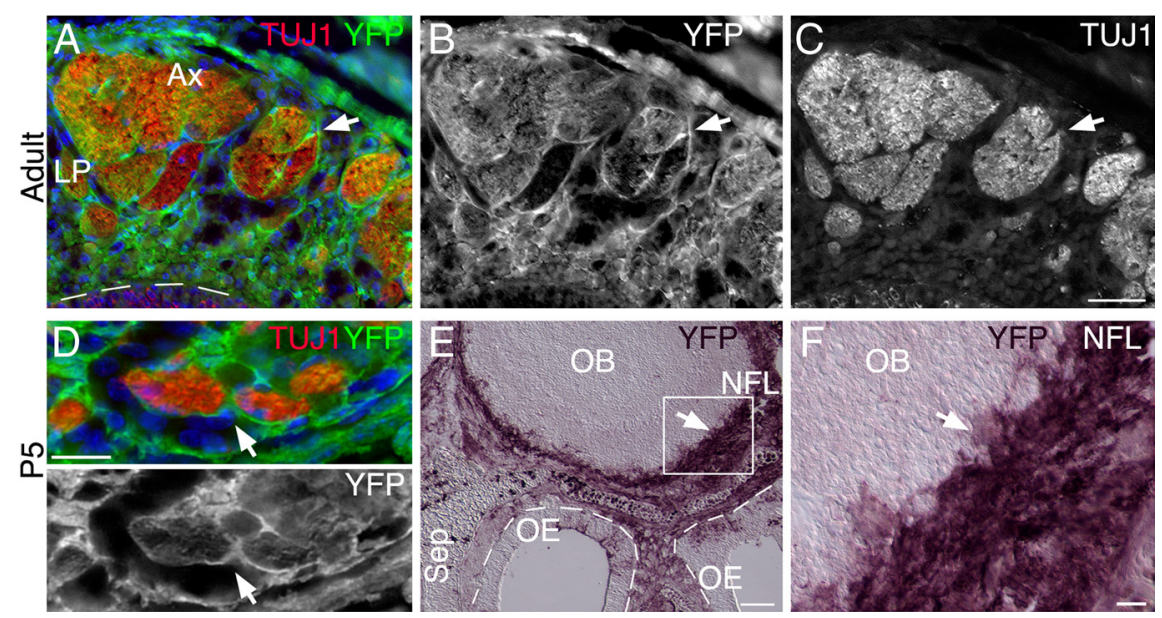

Figure 5. The Pax7 lineage includes olfactory ensheathing cells. $\boldsymbol{A}-\boldsymbol{D}$, In the lamina propria (LP), TUJ1+ (red) 0RN axon bundles (Ax) are surrounded by YFP + olfactory ensheathing cells that arise via a Pax7 lineage (arrows). E, F, YFP + (maroon, VIP munohistochemistry) olfactory ensheathing cells continue to ensheath ORN axons into the nerve fiber layer (NFL) of the olfactory bulb presumptive mesenchymal cells, connective tissues, blood vessels, and/or fibroblasts. Individual signals from YFP (B, D-F) and TUJ1 (C). Sep, Septum. The dashed line indicates the basal lamina. Scale bars: $\boldsymbol{A}-\boldsymbol{C}$ (in $\boldsymbol{C}$, $100 \mu \mathrm{m} ; \boldsymbol{D}, 50 \mu \mathrm{m} ; \boldsymbol{E}, 500 \mu \mathrm{m} ; \boldsymbol{F}, 100 \mu \mathrm{m}$.

region at this developmental stage known to contribute to the $\mathrm{OE}$ proper (Fig. $2 D-F$ ).

At E11.5, of the $630 \pm 36.9$ cells $/ \mathrm{mm}, 102.8 \pm 9.1 \mathrm{cells} / \mathrm{mm}$ express YFP (16.3\%; $p<0.0001$ vs adult) (Table 1$) ; 43 \%$ of YFP+ cells are immature TUJ1+ neurons (Table 3 ), suggesting additional contributions from embryonic progenitors. However, only $35 \%$ of TUJ1 + ORNs (343 of 972 counted) throughout the developing E11.5 OE express YFP (Fig. 7A-D), some of which likely arise via Mash $1+$ neuronal progenitors (Fig. $7 E-H)$. TUJ1 and Mash1 expression was detected also in the few YFP + cells found in the forebrain (Fig. $7 A, E$ ). Abundant YFP+ cells were detected in the lateral nasal process, many of which coexpressed the presumptive embryonic olfactory stem cell marker Sox2 (Kawauchi 

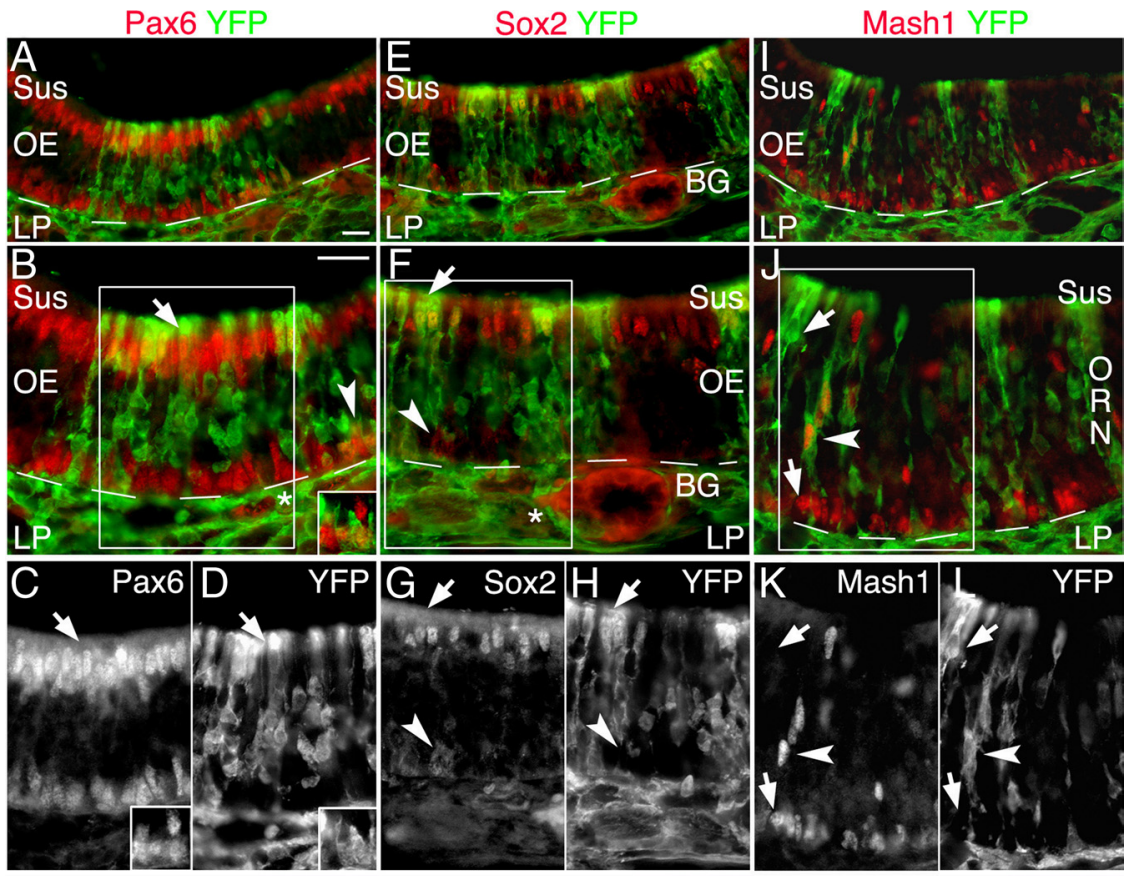

ICAM-1 YFP
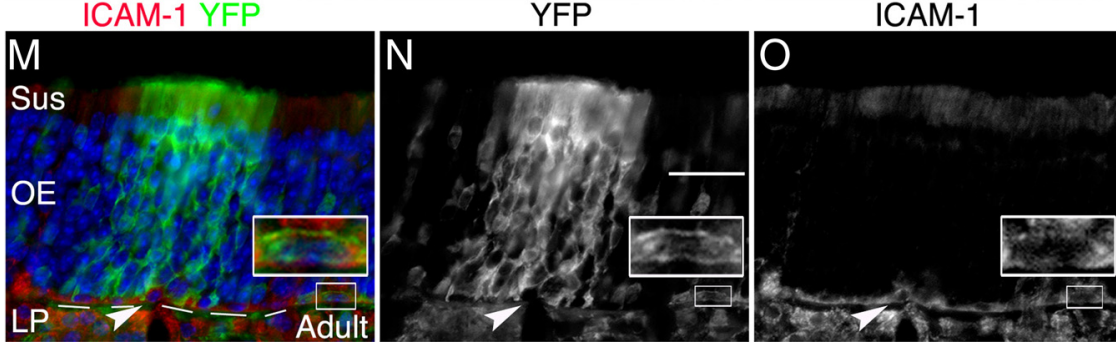

Figure 6. The Pax7 lineage includes Pax6, Sox2, Mash1, and ICAM-1 postnatal olfactory progenitors. A-C, E-G, I-K, Coronal sections of P5 Pax7cre/ROSA YFP mice shows subpopulations of Pax6-positive (A-C), Sox2-positive (E-G), and Mash1-positive $(\boldsymbol{I}-\boldsymbol{K})$ progenitors (all red) that are YFP + (green). B-D) YFP + cells are seen in a subpopulation of Pax6 + sustentacular cells in the apical layer (arrow) and in Pax6 + progenitors in the basal layers (arrowhead and inset). YFP + cells in the lamina propria (LP) are closely juxtaposed to Pax6 + YFP-negative cells (asterisk). $\boldsymbol{F}$ - $\boldsymbol{H}$, In the apical OE, YFP + cells can be detected in a subpopulation of Sox2 + cells (arrow), but less frequently in basal progenitors (arrowhead). Sox2 + cells of Bowman's glands (BG) in the LP are closely juxtaposed by YFP + cells ( $\boldsymbol{F}$; asterisk). $\boldsymbol{J}-\boldsymbol{L}$, YFP is more commonly detected in Mash1+ progenitors (arrowhead) in the

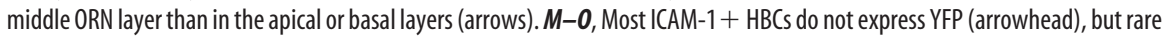
ICAM-1 + YFP + HBCs can be detected in regions where most other cells do not express YFP (inset magnifies boxed region). Boxes indicate regions highlighted in panels showing individual signals from Pax6 (C), Sox2 (G), Mash1 ( $\boldsymbol{K}), \operatorname{ICAM}-1(\mathbf{O})$, and YFP (D, $\boldsymbol{H}$, $\boldsymbol{L}, \boldsymbol{N}$ ). The dashed line indicates the basal lamina. Scale bars: $\boldsymbol{A}, \boldsymbol{E}, \boldsymbol{I}$ (in $\boldsymbol{A}$ ) and $\boldsymbol{B}-\boldsymbol{D}, \boldsymbol{F}-\boldsymbol{H}, \boldsymbol{J}-\boldsymbol{O}$ (in $\boldsymbol{B}), 100 \mu \mathrm{m} ; \boldsymbol{M}-\mathbf{0}$, insets (in $\boldsymbol{N}$ ), $50 \mu \mathrm{m}$.

et al., 2004; Beites et al., 2005) (Fig. 7I-L). In general, those progenitors most highly expressing Pax6 did not express YFP, producing a distinct border between YFP-expressing and highly expressing Pax6 + cells (Fig. $7 M-P$ ). These patterns display a regional restriction and suggest an early embryonic commitment to the Pax7 lineage in multiple embryonic olfactory progenitors, a small proportion of CNS neurons, and neuronal progenitors.

\section{Discussion}

The identity and spatiotemporal location of embryonic OE progenitors, as well as their contributions to the postnatal OE, are primarily unknown. Here, we identified Pax7-expressing cells in the early embryonic OE, which stop expressing Pax7 around E15.5 (Fig. 1). The progeny of embryonic cells expressing Pax7 were genetically fate mapped, leading to the identification of various Pax7 derivatives including olfactory progenitors, nonneuronal cells, CNS, olfactory and vomeronasal neurons, and glia
(Figs. 2-7). These results exemplify the heterogeneity of derivatives generated by embryonic Pax7 precursors.

One limitation of the standard CreloxP fate-mapping approach is the inability to spatiotemporally label Pax7 progenitors, hence the precise developmental time point from which Pax7 precursors first emerge and their temporal lineage allocations remain unknown. Before olfactory placode development (before E10.5), we detected YFP + cells in the anterior neural folds and frontonasal mesenchyme. In the chick embryo, portions of the anterior neural folds are thought to generate the OE (Couly and Le Douarin, 1985; Bhattacharyya and Bronner-Fraser, 2008); however, the frontonasal mesenchyme has no known cellular contribution to the OE. Coincident expression of Pax7 with the YFP reporter in the E10.5 olfactory placode, which subsequently forms the OE, suggests that labeled cells detected within the OE arose via a Pax7+ embryonic olfactory progenitor. The precise origin of olfactory ensheathing cells, however, is currently debated (discussed below).

Pax7 embryonic progenitors compared with postnatal basal cell progenitors Lineage tracing of GBCs (Goldstein et al., 1998; Huard et al., 1998; Chen et al., 2004) and HBCs (Leung et al., 2007; Iwai et al., 2008) has shown that the most potent clones generate HBCs, GBCs, ORNs, sustentacular cells, and Bowman's duct/gland cells. HBCs can also produce olfactory ensheathing glia in vitro (Carter et al., 2004). However, neither GBCs nor HBCs have demonstrated the in vivo production of olfactory ensheathing cells. Thus, compared with postnatal basal progenitors, Pax7+ embryonic progenitors share some common cellular descendants but are unique in their ability to additionally produce olfactory ensheathing glia and CNS neurons. These analyses suggest a possible switch to more restricted progenitors in the OE with aging.

\section{Pax7 embryonic progenitors compared with embryonic olfactory progenitors}

Transgenic mice used to fate map embryonic olfactory progenitors identified either glia-restricted (Murdoch and Roskams, 2007) or neuron-restricted (Duggan et al., 2008; Murdoch and Roskams, 2008) embryonic progenitors but not progenitors that contribute to non-neuronal cells, neurons, and glia, such as Pax7 descendants (Figs. 2, 4-6). Additionally, Pax7 neuronal and sustentacular cell descendants revealed a unique pattern of YFP+ progeny not seen in the aforementioned lineage tracing studies, which is found in patches throughout the postnatal OE. This pattern could not be attributed to the instability of Pax7 expres- 
sion associated with Cre in the Pax7 locus (supplemental Fig S5, available at www. jneurosci.org as supplemental material).

The mosaic pattern of YFP expression could alternatively be attributable to incomplete recombination. However, since Pax7 expression is not altered, Cre recombinase expression is also likely unaltered, and thus full recombination should result. Multiple data support this view. Incomplete recombination would lead to random excision events resulting in variable YFP expression patterns. Contrary to this, the YFP expression pattern is consistent between equivalently staged samples and in an independent transgenic reporter line, R26R, expressing the LacZ gene (data not shown). The overall YFP expression pattern seen in Pax7-cre/ROSA YFP embryos is consistent with that reported previously using several transgenic mouse lines [Pax7-LacZ (Relaix et al., 2004), Pax7-ZsGreen (Bosnakovski et al., 2008), and Pax7-cre/ROSA LacZ mice (Keller et al., 2004)]. Finally, although the signal intensity of Pax7 protein expression in the olfactory placode and OE is much lower compared with the frontonasal mesenchyme, all Pax7+ cells in the olfactory placode appear to express the YFP reporter (Fig. 2). These results do not support an "incomplete recombination" model and suggest that the pattern of YFP expression seen in Pax7-cre/ ROSA YFP mice is reflective of complete recombination events that are Pax7 driven. Discrediting these possible technical caveats highlights the surprising nature of the varied cell types and mosaic distribution of Pax7 derivatives, calling for a mechanistic explanation.

Our study exposes an intriguing difference in the proportion of Pax7-derived cells contributed to the OE versus those contributed to olfactory ensheathing cells. Whereas the first set is composed of a modest and declining contribution, the second set seems stable and robust. A possible explanation for such disparate contributions is that the precursors for both $\mathrm{OE}$ and olfactory ensheathing cells are the same (Fig. $8 A-D$ ), and simply one fate is favored, whereas the others are temporally and quantitatively restricted. Alternatively, different Pax7-expressing progenitors could be responsible for OE versus olfactory ensheathing cell derivation (Fig. 8), each displaying different regulation of proliferation, survival, and differentiation.

The mosaic pattern of Pax7 progeny suggests a considerable contribution from Pax7-negative progenitors to the postnatal $\mathrm{OE}$. Indeed, as the $\mathrm{OE}$ expands during embryonic to adult stages, there is a 27 -fold decrease (16.3\% divided by $0.6 \%$ ) (Table 1) in the percentage of total cells expressing YFP, even though the average number of YFP + cells does not appreciably increase beyond P5 (Table 1). Decreases in the YFP contributions to the $\mathrm{OE}$ are seen in all cell types examined (Table 1). The proportionate decline in Pax7-derived OE
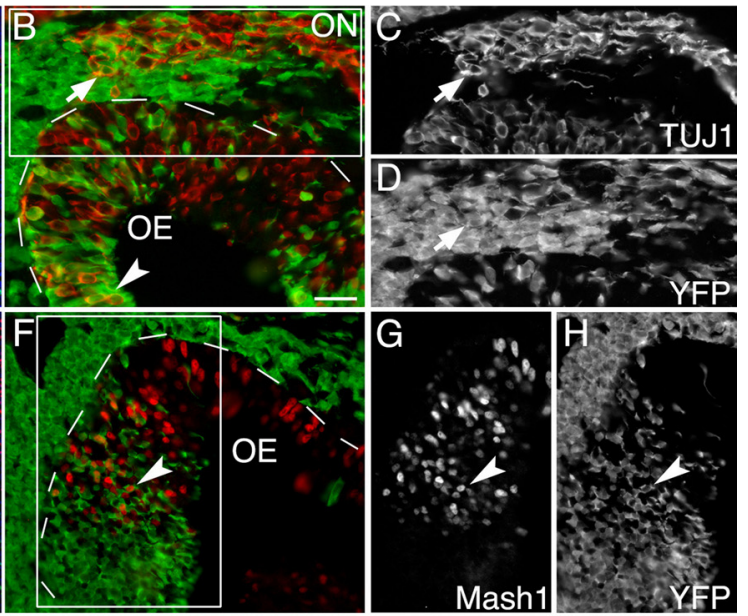

Figure 7. Subpopulations of embryonic olfactory progenitors arise via Pax7 lineage. $A, E, I, M$, YFP (green) is detected as early 政 N. Boxes indicate regions highlighted in panels showing individual signals from TUJ1 (C), Mash1 (G), Sox2 (K), Pax6 (0), and YFP $(\boldsymbol{D}, \boldsymbol{H}, \boldsymbol{L}, \boldsymbol{P})$. The dashed line indicates the basal lamina. Scale bars: $\boldsymbol{A}, \boldsymbol{E}, \boldsymbol{I}, \boldsymbol{M}$, (in $\boldsymbol{A}$ ), all others (in $\boldsymbol{B}), 100 \mu \mathrm{m}$.

progeny with aging could be explained by a progressive depletion in Pax7 progenitors. This makes obvious the participation of alternative, yet undescribed Pax7-negative progenitors, which contribute more highly throughout the OE. If these alternative progenitors are restricted to embryonic stages, like Pax7-precursors, they likely possess greater survival and/or proliferative potential in comparison. Another option considers a set of progenitors present during both embryonic and postnatal development that is responsive to cues for embryonic tissue expansion and postnatal maintenance.

How might local expression of Pax7 define a unique progenitor domain? Regional expression and level of transcription factors, as seen in the developing spinal cord (Briscoe et al., 2000; Bel-Vialar et al., 2007) and detected here between Pax7 and Pax6, could form initial progenitor zones responsible for the fine architecture of the OE. The unique transcriptional profiles characteristic of independent progenitors may confer proliferative and/or survival advantages compared with their competitors. Additional analysis of the contribution of Pax6 and other putative progenitors may resolve these seemingly random mosaic patterns into 


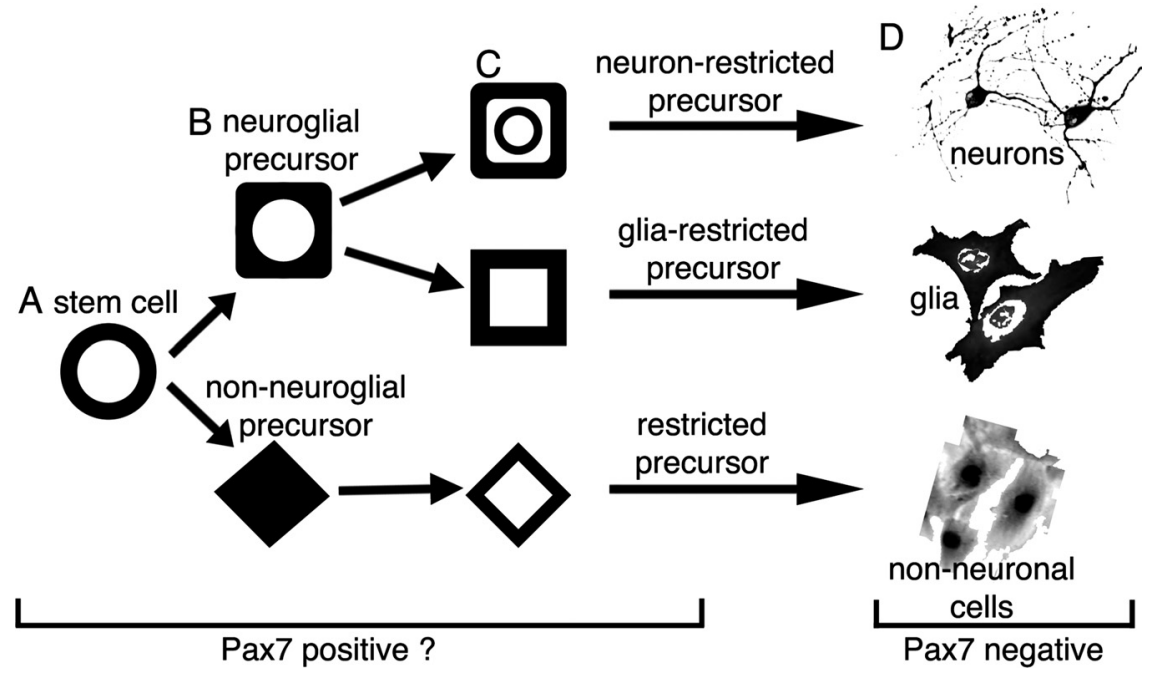

Figure 8. Potential lineages of embryonic Pax7 + olfactory progenitors. Non-neuronal cells, neurons, and olfactory ensheathing glia, which no longer express Pax $7(\boldsymbol{D})$, arise via embryonic Pax7 + progenitors. $\boldsymbol{A}-\boldsymbol{C}$, Potential Pax7 olfactory lineages include a multipotent Pax7 + stem cell $(\boldsymbol{A})$ or more restricted Pax7 + precursor $(\boldsymbol{B})$, each with the capacity to clonally produce multiple cell types, or independent lineages through cell type-restricted precursors $(\boldsymbol{C})$, dependent on the cellular potency of the precursor that first expresses Pax7.

more coherent organizational domains. Importantly, our capacity to identify additional OE progenitors and the expression patterns of their progeny is currently limited by a lack of markers at earlier stages.

\section{Pax7+ muscle and neural crest cells compared with embryonic olfactory progenitors}

In muscle, Pax7+ satellite cells are stem/progenitor cells that contribute to postnatal muscle growth and regeneration (Charge and Rudnicki, 2004). Like Pax7 + muscle satellite cells (Collins et al., 2005; Kuang et al., 2007), Pax7+ olfactory precursors likely also represent a hierarchical heterogeneous progenitor cell population with mostly committed progenitors, but whose stem cell function remains to be tested.

Neural crest cells are multipotent migratory cells critical for vertebrate development that contribute to multiple tissues including the peripheral nervous system, cardiovascular, craniofacial bone, and cartilage (Kirby et al., 1983; Le Douarin et al., 1998; Chai et al., 2000; Jiang et al., 2000; Baker, 2005; Nakamura et al., 2006). In the chick, Pax7 has been identified as an early marker of neural crest cells that is required for neural crest development (Basch et al., 2006). Accordingly, Pax7 is expressed in neural crest cell precursors in the dorsal neural tube (Jostes et al., 1991; Mansouri et al., 1996; Lang et al., 2003; Basch et al., 2006), and Pax7-cre/ROSA YFP mice label neural crest derivatives (B. Murdoch and M. I. Garcia-Castro, manuscript in preparation). Interestingly, in dorsal root ganglia, we have detected the Pax7 lineage in neurons but not in S100 $\beta+$ peripheral glia (data not shown), suggesting that subpopulations of peripheral and olfactory sensory neurons share similar transcriptional lineage profiles.

Our data lead one to question whether neural crest cells contribute to some of the OE derivatives identified here, olfactory ensheathing cells in particular. Quail chick transplants of the anterior neural folds, a region with Pax7 expression (Basch et al., 2006; Otto et al., 2006; Khudyakov and Bronner-Fraser, 2009), contribute to the olfactory placodes (Couly and Le Douarin, 1985; Bhattacharyya and Bronner-Fraser, 2008), from which olfactory ensheathing cells are thought to be derived (Farbman,
1992). Evidence from zebrafish, however, suggests that at least some olfactory ensheathing cells could have a neural crest origin (Whitlock, 2004). Little is known about the lineage of olfactory ensheathing cells in the mouse, beyond that they arise via a BLBP+ precursor (Murdoch and Roskams, 2007). The Pax7 progeny detected in the olfactory mucosa of our Pax7-cre/ROSA YFP mice could arise via Pax7-expressing cells of the olfactory placode, from preplacodal cells, or from neural crest cells. Our experimental model cannot resolve this issue, but transgenic mice used to fate map neural crest derivatives, like Wnt1-cre/reporters (Chai et al., 2000; Jiang et al., 2000), offer encouraging alternatives.

Here we identify embryonic Pax7+ progenitors, whose postnatal progeny reveal novel spatiotemporal patterning of the $\mathrm{OE}$ and contribute to multiple cell lineages including neurons, glia, and non-neuronal cells. We propose that Pax7 expression thus identifies the first documented population of embryonic progenitors capable of producing multiple committed olfactory cell types in vivo.

\section{References}

Baker C (2005) Neural crest and cranial ectodermal placodes. In: Developmental neurobiology (Jocobson M, ed), pp 67-127. New York: Springer.

Basch ML, Bronner-Fraser M, Garcia-Castro MI (2006) Specification of the neural crest occurs during gastrulation and requires Pax7. Nature 441:218-222.

Beites CL, Kawauchi S, Crocker CE, Calof AL (2005) Identification and molecular regulation of neural stem cells in the olfactory epithelium. Exp Cell Res 306:309-316.

Bel-Vialar S, Medevielle F, Pituello F (2007) The on/off of Pax6 controls the tempo of neuronal differentiation in the developing spinal cord. Dev Biol 305:659-673.

Bhattacharyya S, Bronner-Fraser M (2008) Competence, specification and commitment to an olfactory placode fate. Development 135:4165-4177.

Blake JA, Thomas M, Thompson JA, White R, Ziman M (2008) Perplexing Pax: from puzzle to paradigm. Dev Dyn 237:2791-2803.

Bosnakovski D, Xu Z, Li W, Thet S, Cleaver O, Perlingeiro RC, Kyba M (2008) Prospective isolation of skeletal muscle stem cells with a Pax7 reporter. Stem Cells 26:3194-3204.

Briscoe J, Pierani A, Jessell TM, Ericson J (2000) A homeodomain protein code specifies progenitor cell identity and neuronal fate in the ventral neural tube. Cell 101:435-445.

Carter LA, MacDonald JL, Roskams AJ (2004) Olfactory horizontal basal cells demonstrate a conserved multipotent progenitor phenotype. J Neurosci 24:5670-5683.

Cau E, Gradwohl G, Fode C, Guillemot F (1997) Mash1 activates a cascade of bHLH regulators in olfactory neuron progenitors. Development 124:1611-1621.

Chai Y, Jiang X, Ito Y, Bringas P Jr, Han J, Rowitch DH, Soriano P, McMahon AP, Sucov HM (2000) Fate of the mammalian cranial neural crest during tooth and mandibular morphogenesis. Development 127:1671-1679.

Charge SB, Rudnicki MA (2004) Cellular and molecular regulation of muscle regeneration. Physiol Rev 84:209-238.

Chen B, Kim EH, Xu PX (2009) Initiation of olfactory placode development and neurogenesis is blocked in mice lacking both Sixl and Six4. Dev Biol 326:75-85.

Chen X, Fang H, Schwob JE (2004) Multipotency of purified, transplanted globose basal cells in olfactory epithelium. J Comp Neurol 469:457-474. Collins CA, Olsen I, Zammit PS, Heslop L, Petrie A, Partridge TA, Morgan JE 
(2005) Stem cell function, self-renewal, and behavioral heterogeneity of cells from the adult muscle satellite cell niche. Cell 122:289-301.

Couly GF, Le Douarin NM (1985) Mapping of the early neural primordium in quail-chick chimeras. I. Developmental relationships between placodes, facial ectoderm, and prosencephalon. Dev Biol 110:422-439.

Davis JA, Reed RR (1996) Role of Olf-1 and Pax-6 transcription factors in neurodevelopment. J Neurosci 16:5082-5094.

Duggan CD, Demaria S, Baudhuin A, Stafford D, Ngai J (2008) Foxg1 is required for development of the vertebrate olfactory system. J Neurosci 28:5229-5239.

Dulac C (2000) Sensory coding of pheromone signals in mammals. Curr Opin Neurobiol 10:511-518.

Farbman AI (1992) Cell biology of olfaction. Cambridge, UK: Cambridge UP.

Getchell TV, Margolis FL, Getchell ML (1984) Perireceptor and receptor events in vertebrate olfaction. Prog Neurobiol 23:317-345.

Goldstein BJ, Schwob JE (1996) Analysis of the globose basal cell compartment in rat olfactory epithelium using GBC-1, a new monoclonal antibody against globose basal cells. J Neurosci 16:4005-4016.

Goldstein BJ, Fang H, Youngentob SL, Schwob JE (1998) Transplantation of multipotent progenitors from the adult olfactory epithelium. Neuroreport 9:1611-1617.

Gordon MK, Mumm JS, Davis RA, Holcomb JD, Calof AL (1995) Dynamics of MASH1 expression in vitro and in vivo suggest a non-stem cell site of MASH1 action in the olfactory receptor neuron lineage. Mol Cell Neurosci 6:363-379.

Graziadei GA, Graziadei PP (1979) Neurogenesis and neuron regeneration in the olfactory system of mammals. II. Degeneration and reconstitution of the olfactory sensory neurons after axotomy. J Neurocytol 8:197-213.

Huard JM, Youngentob SL, Goldstein BJ, Luskin MB, Schwob JE (1998) Adult olfactory epithelium contains multipotent progenitors that give rise to neurons and non-neural cells. J Comp Neurol 400:469-486.

Iwai N, Zhou Z, Roop DR, Behringer RR (2008) Horizontal basal cells are multipotent progenitors in normal and injured adult olfactory epithelium. Stem Cells 26:1298-1306.

Jiang X, Rowitch DH, Soriano P, McMahon AP, Sucov HM (2000) Fate of the mammalian cardiac neural crest. Development 127:1607-1616.

Jostes B, Walther C, Gruss P (1991) The murine paired box gene, Pax7, is expressed specifically during the development of the nervous and muscular system. Mech Dev 33:27-37.

Joyner AL, Zervas M (2006) Genetic inducible fate mapping in mouse: establishing genetic lineages and defining genetic neuroanatomy in the nervous system. Dev Dyn 235:2376-2385.

Kawauchi S, Beites CL, Crocker CE, Wu HH, Bonnin A, Murray R, Calof AL (2004) Molecular signals regulating proliferation of stem and progenitor cells in mouse olfactory epithelium. Dev Neurosci 26:166-180.

Kawauchi S, Shou J, Santos R, Hebert JM, McConnell SK, Mason I, Calof AL (2005) Fgf8 expression defines a morphogenetic center required for olfactory neurogenesis and nasal cavity development in the mouse. Development 132:5211-5223.

Keller C, Hansen MS, Coffin CM, Capecchi MR (2004) Pax3:Fkhr interferes with embryonic Pax3 and Pax7 function: implications for alveolar rhabdomyosarcoma cell of origin. Genes Dev 18:2608-2613.

Khudyakov J, Bronner-Fraser M (2009) Comprehensive spatiotemporal analysis of early chick neural crest network genes. Dev Dyn 238:716-723.

Kirby ML, Gale TF, Stewart DE (1983) Neural crest cells contribute to normal aorticopulmonary septation. Science 220:1059-1061.

Kocsis JD, Lankford KL, Sasaki M, Radtke C (2009) Unique in vivo properties of olfactory ensheathing cells that may contribute to neural repair and protection following spinal cord injury. Neurosci Lett 456:137-142.
Kuang S, Kuroda K, Le Grand F, Rudnicki MA (2007) Asymmetric selfrenewal and commitment of satellite stem cells in muscle. Cell 129:999-1010.

LaMantia AS, Bhasin N, Rhodes K, Heemskerk J (2000) Mesenchymal/epithelial induction mediates olfactory pathway formation. Neuron 28:411-425.

Lang D, Brown CB, Milewski R, Jiang YQ, Lu MM, Epstein JA (2003) Distinct enhancers regulate neural expression of Pax7. Genomics 82: 553-560.

Lang D, Powell SK, Plummer RS, Young KP, Ruggeri BA (2007) PAX genes: roles in development, pathophysiology, and cancer. Biochem Pharmacol 73:1-14.

Le Douarin NM, Teillet MA, Catala M (1998) Neurulation in amniote vertebrates: a novel view deduced from the use of quail-chick chimeras. Int $J$ Dev Biol 42:909-916.

Leung CT, Coulombe PA, Reed RR (2007) Contribution of olfactory neural stem cells to tissue maintenance and regeneration. Nat Neurosci 10:720-726.

Mansouri A, Stoykova A, Torres M, Gruss P (1996) Dysgenesis of cephalic neural crest derivatives in Pax7-/- mutant mice. Development 122:831-838.

McKinnell IW, Ishibashi J, Le Grand F, Punch VG, Addicks GC, Greenblatt JF, Dilworth FJ, Rudnicki MA (2008) Pax7 activates myogenic genes by recruitment of a histone methyltransferase complex. Nat Cell Biol 10:77-84.

Murdoch B, Roskams AJ (2007) Olfactory epithelium progenitors: insights from transgenic mice and in vitro biology. J Mol Histol 38:581-599.

Murdoch B, Roskams AJ (2008) A novel embryonic nestin-expressing radial glia-like progenitor gives rise to zonally restricted olfactory and vomeronasal neurons. J Neurosci 28:4271-4282.

Nakamura T, Colbert MC, Robbins J (2006) Neural crest cells retain multipotential characteristics in the developing valves and label the cardiac conduction system. Circ Res 98:1547-1554.

Otto A, Schmidt C, Patel K (2006) Pax3 and Pax7 expression and regulation in the avian embryo. Anat Embryol (Berl) 211:293-310.

Raisman G, Li Y (2007) Repair of neural pathways by olfactory ensheathing cells. Nat Rev Neurosci 8:312-319.

Relaix F, Rocancourt D, Mansouri A, Buckingham M (2004) Divergent functions of murine Pax3 and Pax7 in limb muscle development. Genes Dev 18:1088-1105.

Richter MW, Roskams AJ (2008) Olfactory ensheathing cell transplantation following spinal cord injury: hype or hope? Exp Neurol 209:353-367.

Schwob JE (2002) Neural regeneration and the peripheral olfactory system. Anat Rec 269:33-49.

Shou J, Rim PC, Calof AL (1999) BMPs inhibit neurogenesis by a mechanism involving degradation of a transcription factor. Nat Neurosci 2:339-345.

Soriano P (1999) Generalized lacZ expression with the ROSA26 Cre reporter strain. Nat Genet 21:70-71.

Srinivas S, Watanabe T, Lin CS, William CM, Tanabe Y, Jessell TM, Costantini F (2001) Cre reporter strains produced by targeted insertion of EYFP and ECFP into the ROSA26 locus. BMC Dev Biol 1:4.

Stoykova A, Gruss P (1994) Roles of Pax-genes in developing and adult brain as suggested by expression patterns. J Neurosci 14:1395-1412.

Weissman IL, Anderson DJ, Gage F (2001) Stem and progenitor cells: origins, phenotypes, lineage commitments, and transdifferentiations. Annu Rev Cell Dev Biol 17:387-403.

Whitlock KE (2004) A new model for olfactory placode development. Brain Behav Evol 64:126-140. 